\title{
TITLE:
}

\section{Coalitions, incentives, and risk sharing}

\author{
AUTHOR(S):
}

Itoh, Hideshi

\section{CITATION:}

Itoh, Hideshi. Coalitions, incentives, and risk sharing. 京都大学経済学部 Working Paper 1990, 10

ISSUE DATE:

1990-12

URL:

http://hdl.handle.net/2433/37905

RIGHT: 
COALITIONS, INCENTIVES, AND RISK SHARING

by

Hideshi Itoh

Faculty of Economics

Kyoto University

Faculty of Economics,

Kyoto University, Kyoto, 606 JAPAN 
COALITIONS, INCENTIVES, AND RISK SHARING

by

Hideshi Itoh

Faculty of Economics

Kyoto University

December 1990 


\title{
COALITIONS, INCENTIVES, AND RISK SHARING*
}

\author{
by \\ HIDESHI ITOH \\ Department of Economics \\ Kyoto University \\ Sakyō-ku, Kyoto 606, Japan
}

December 1990

Journal of Economic Literature Classification Numbers: 026, 511, 821.

* This paper is a revision of my unpublished manuscript "Collusion, Incentives, and Risk Sharing." I am grateful to David Kreps for first suggesting the issue of this paper to me during his supervision of my doctoral thesis submitted to Stanford University, and to Bengt Holmstrom, John McMillan, Masahiro Okuno-Fujiwara, Jean Tirole, and the participants at the fourth Japan-U.S. symposium at NYU and the seminars at MIT, Pennsylvania, UC San Diego, and Yale SOM for their helpful comments. 


\begin{abstract}
This paper analyzes coalitional behavior in principal-multiagent relationships with moral hazard, and identifies cases where the principal prefers agents to form a coalition via side contracting. The paper first shows that when agents' efforts are mutually unobservable so that their side contracts cannot be contingent on their efforts, the possibility of mutual insurance through monetary side contracts never makes the principal better off. It is then shown that when the agents can monitor each other's efforts perfectly, coordination in effort choice through side contracts contingent on efforts and outputs enables the principal to reduce the cost of implementing given efforts. This result holds when no production externality exists and noise terms are independent, when there is team production and the agents are sufficiently homogeneous, or when production externalities such as mutual "help" are important and there is a pressure toward "egalitarianism."
\end{abstract}

KEYWORDS: Principal-multiagent relationships, coalition, side contracts, moral hazard, risk sharing, mutual monitoring. 


\section{INTRODUCTION}

This paper concerns principal-multiagent relationships. Much of the recent literature in this field focuses on the problem associated with the multiplicity of Nash equilibrium (Demski and Sappington, 1984; Ma, 1988; Ma, Moore, and Turnbull, 1989; Mookherjee, 1984; Mookherjee and Reichelstein, 1990). In her relation with agents, the principal designs a contract for each agent so as to elicit desirable efforts as a Nash equilibrium of the noncooperative effort choice game played by the agents. The literature points out that in such a situation, given contracts offered by the principal, there often exists another Nash equilibrium preferred by all the agents to the one the principal wishes to implement. It is thus likely that the agents agree to select their preferred equilibrium, and this sort of collusive behavior is costly to the principal. Some of the authors listed above show that by allowing agents to send auxiliary messages about their private information (state of nature or discretionary action), the problem can be resolved costlessly either under adverse selection (Ma, Moore, and Turnbull; Mookherjee and Reichelstein) or under moral hazard (Ma).

In this paper, I consider another related problem in a multiagent organization: the possibility of coalitions through side contracts. One of the recent criticisms on the standard principal-multiagent analyses, also relevant to those cited above, is that the relationship is characterized by a single grand contract designed by the principal: "All members of the organization are linked by a grand contract, and their interaction is limited to procedures specified by this contract." (Tirole, 1988, p. 461.) In practice, agents are likely to engage in side trades (pecuniary or nonpecuniary, implicit or explicit) that are not directly controllable to the principal because she cannot observe them. The importance of such coalitional behavior in organizations has been extensively discussed by sociologists for a long time. Related remarks are found in the recent reviews of economic theories of organizations by sociologists (Baron, 1988, Granovetter, 1985, Perrow, 1986): They criticize economists' overemphasis on formal properties of organizations and argue that informal aspects of organizations such as work norms and social relations are no less important.

Following Tirole (1986, 1988), I adopt the following full-side-contract assumption: a group of members can costlessly write any side contract based on information commonly observable among them. These side contracts may not be enforceable explicitly when they are contingent on private information shared among coalitional members. This full-side-contract assumption 
thus can be rephrased as follows: it is assumed that a group of members, when forming a coalition, abide by their promises built on their common information with probability one. This assumption is clearly extreme. However, it also appears an extreme assumption that promises that are not self-enforcing are respected with probability zero. ${ }^{1}$ As a first step, this paper employs the extreme approach which is the other side of the traditional one. ${ }^{2}$

Side contracts in an organization can be detrimental (the case of collusion) or beneficial (the case of cooperation) to the organization as a whole. The case of collusion is analyzed in Tirole (1986). He considers a model of the three-tier organization with a principal, a supervisor, and an agent. After signing a grand contract, the agent observes privately the true value of an uncertain productivity parameter, and then selects effort. The supervisor can sometimes obtain, without any input, evidence on the true productivity; and report it to the principal. Under the full-side-contract assumption, Tirole shows that although the principal can design an initial contract preventing any further side contract (the original contract being coalitionproof), the possibility of side contracting at the nexus of information (between supervisor and agent) reduces the net payoff to the principal.

The main purpose of this paper is to seek for cases in which coalition among agents via side contracts leads to cooperation, benefiting the principal. The importance of cooperation within organizations is recently discussed in many contexts. For example, the work-team concept has recently become popular in the United States. Economists are generally not as excited about the idea of teamwork to improve productivity as psychologists, sociologists, or practitioners are. The reason is the problem of motivation. Compared with unambiguous division of labor and individual-based pay schemes, teamwork, along with group-based pay, weakens the connection between pay and the performance of each individual worker, and hence is expected to give greater incentives to shirk to workers. Several researchers argue that what teamwork and group-based pay do is to modify otherwise inefficient interaction among self-

1 In fact, there is experimental evidence that people have "words of honor." See Section 8.

2 An alternative approach would be to develop a repeated-game model of the agency relationship to make coalitions self-enforcing (via reputation). A successful development of such a model would answer the question of how the results obtained in this paper under the full-sidecontract assumption would differ in intermediate cases of promises followed with probability between zero and one. The costs of that approach are that they tend to become complex and messy without adding more implications. As a first step, the easier approach is taken in this paper, although the importance of the development of the alternative approach is not meant to be underemphasized. 
interested workers toward a cooperative solution via mutual monitoring and sanctioning, or by changing the goals of the workers. (See, for example, Nalbantian (1988) and Levine and Tyson (1990).) While this assertion itself must be examined more carefully, it is still not clear, even after accepting the argument, whether group behavior of workers is in fact beneficial to the employer; in particular, taking into account the emphasis on the detrimental effects of coalitional behavior and on "competitive" incentive schemes such as relative performance evaluation and tournaments in the existing literature. ${ }^{3}$

To find some answers to this question, I analyze a Grossman and Hart (1983) type model of a principal/two agents relationship. Each agent is risk averse and effort averse, and selects unobservable effort given a contract offered by the principal. In the coalition-free world, the principal designs initial contracts contingent on contractible outputs so as to induce the agents to select a desirable effort pair as a Nash equilibrium of the simultaneous effort choice game. My focus is on "lateral" coalition between the agents playing effort choice games. This contrasts with Tirole's model which focuses on "vertical" coalition and the manipulation of information about the agent by the supervisor.

The main result of the paper can be most clearly presented in the situation in which neither of production externality nor correlation between noise terms exists. It is now well known that in such a case the optimal compensation scheme for each agent is individual-based when side contracting is infeasible: his pay is independent of the other agent's output (Holmström, 1982, Mookherjee, 1984). I show that in such a situation, the principal can implement a given effort pair with lower costs when the agents can side contract on efforts, choosing a Pareto optimal effort pair, than when no side contract occurs. The reason is that the principal can impose less risk on the agents without weakening their incentives to select a given effort pair. The principal can do so not because the agents can engage in mutual insurance between them but because they can monitor each other's effort and hence can coordinate their effort choice. In fact, it is shown that when the agents cannot coordinate their effort choice (e.g., because efforts are mutually unobservable), and when the role of side contracts is only that of mutual insurance between the agents (across publicly observable states), the principal is never better

3 In another paper (Itoh, 1990), I discuss in more detail the recent trend toward cooperation in practice, and have applied the results obtained in this paper and other work of mine to explain why "cooperation" can be important from incentive viewpoints, in contrast to the current trend in incentive theory emphasizing "competition" as incentive schemes. 
off when the agents behave as a group.

An interesting corollary of the result stated above is that in order to elicit the value of cooperation in effort choice, the principal must discard individual-based incentive schemes: when no production externality exists, whether the agents behave noncooperatively or cooperatively does not matter under individual-based schemes. Some forms of interdependent schemes, in which an agent is paid more the better the performance of the other agent is, must be adopted, despite no information content in an agent's output concerning the other agent's effort. $^{4}$

The logic explained above extends to more general cases in which there exist interactions between agents in the absence of coalition. I present an analysis of two such cases, the case of team production where only the aggregate outputs are publicly observable, and an example of production externalities in which each agent can "help" the other agent. It is shown that under some conditions, the benefits of side contacts are realized in both cases. The logic is exactly the same as in the previous independent case.

These contexts analyzed in the paper are clearly in contrast to the multiagent situation previously analyzed by many economists, the case in which the principal wants to encourage "competition" among agents via relative performance evaluation (Baiman and Demski, 1980; Green and Stokey, 1983; Holmström, 1982; Lazear and Rosen, 1981; Mookherjee, 1984; and Nalebuff and Stiglitz, 1983). If production by an agent is independent of the other agent's effort, the probability distribution of outputs exhibits the monotone likelihood ratio property (Milgrom, 1981), and systematic risk exists so that relative performance evaluation is optimal, then each agent is paid more the lower the output of the other agent is. In particular, if pay in the absence of side contracts is determined by rank-order tournaments, improving risk sharing generally weakens the agents' incentives to select the efforts the principal wishes to implement. Effort coordination is thus detrimental in such a case.

There is one important caveat concerning the comparative analysis in this paper. The benchmark case of no coalition is the standard second-best solution attained by the optimal incentive contract. That is, the possibility that the principal designs more complex revelation

4 Laffont (1990) presents a similar result, while the logic is quite different. In his model, individual-based pay schemes may be avoided by the principal because they may create opportunities for a supervisor to "exploit" his agents via a design of games not observable to the principal. 
mechanisms is excluded. When efforts are not mutually observable between agents, this restriction is without loss of generality. However, when efforts are mutual observable, if agents do not side trade, the principal could attain the first-best outcome by an appropriate direct revelation mechanism á la Ma (1988). Thus, some readers may argue that the benchmark in this case should be the first-best, and hence side contracting by agents contingent on efforts would not improve the principal's welfare.

Such mechanisms are assumed to be infeasible because they require that the principal be able to contract on efforts. The underlying assumption adopted in this paper is that contracts can be contingent only on what the relevant parties can observe: The principal cannot contract on efforts, even though agents can report them under revelation mechanisms. The reason may be costs of communication (she cannot exactly understand what is reported), or more importantly, costs of writing contracts (she cannot specify efforts completely in an initial contract, as in Williamson (1985) and Grossman and Hart (1986)). On the other hand, when efforts are mutually observable by agents, they can contract on efforts implicitly or explicitly in their side contracts. In this sense, this paper is not in a complete contracting framework, but in a "semi-complete" contracting framework. And coalition among agents may expand the set of feasible contracts when they can contract on their private information not observable to the principal. ${ }^{5}$

Note that such revelation mechanisms would play no role in the world of full side contracting even if explicit contracts on the agents' reports about their efforts were feasible. There, once communication channels opened, the agents would collude in communication stages. I show that there is no coalition-proof revelation mechanism improving the principal's welfare from the case of effort coordination via side contracts without communication with the principal. The principal thus would not attempt to centralize the information about the agents' efforts. ${ }^{6}$

Recently, the benefits of side contracts have been analyzed independently by several economists (Holmstrom and Milgrom, 1990; Macho-Stadler and Pérez-Castrillo, 1990; Ramakrishnan and Thakor, 1990; Varian, 1990). They also reach the results similar to some of those found in this paper. I will mention their work later in appropriate places.

5 I am grateful to Jean Tirole for suggesting this interpretation.

${ }^{6}$ Because of this, I call cooperation in this paper delegated cooperation in Itoh (1990). 
The rest of the paper is organized as follows. Section 2 analyzes the possibility of side contracting contingent on outputs only. Section 3 examines the effect of side contracts contingent on effort choice when production is individualistic and the optimal coalition-free contract is individual-based. Sections 4 and 5 are extensions to cases of team production and production externalities, respectively. Comparison with relative performance evaluation is discussed in Section 6 . Section 7 shows that revelation mechanisms do not improve the principal's welfare. Section 8 is concluding remarks.

\section{Mutual Risk Sharing through Side Contracting}

This section presents a general model of the principal-multiagent relationship with the possibility of side contracting among agents contingent only on publicly observable measures. Throughout the section, it is assumed that each agent cannot observe the effort chosen by the other agents. They hence cannot enforce Pareto optimal effort choice through side trades. The role of side contracts is then that of mutual risk sharing among agents. In this section I show that the possibility of mutual insurance alone never benefits the principal. To this end, all possible side contracts among the agents are incorporated into the original contract designed by the principal such that any further contracting is prevented. The principal can design such a coalition-proof contract without any loss. While side transfers never occur when the original contract is formulated in such a way, there being the possibility of side contracting reduces the principal's net payoff.

There are one principal and two agents, indexed by $n=1,2$. Agent $n$ selects effort $e_{n}$ from a compact set of feasible efforts, which we assume is a subset of a finite dimensional Euclidean space. Output $x^{n}$ of agent $n$ depends on the effort pair $\left(e_{1}, e_{2}\right)$ selected by two agents and a noise term through a production function. There are $I_{n}$ possible output levels $x_{1}^{n}<\cdots<x_{I_{n}}^{n}$ for agent $n$. Each $i \in \Omega_{n} \equiv\left\{1, \ldots, I_{n}\right\}$ is called an outcome of agent $n$. Let $P_{i j}\left(e_{1}, e_{2}\right)$ be the joint probability of output pair $\left(x_{i}^{1}, x_{j}^{2}\right)$ induced by the production functions when the effort pair $\left(e_{1}, e_{2}\right)$ is chosen. It is assumed that there is no moving support: $P_{i j}\left(e_{1}, e_{2}\right)$ is strictly positive for each $\left(e_{1}, e_{2}\right)$ and $(i, j)$.

The preference of each agent is represented by a von Neumann-Morgenstern utility function. Agent $n$ has an additively separable utility function $V_{n}(w)-G_{n}\left(e_{n}\right)$ where $w$ is remuneration from the principal. $V_{n}$ is assumed to be twice-continuously differentiable, strictly 
increasing, and strictly concave: agents are assumed to be risk averse. $G_{n}\left(e_{n}\right)$ represents a disutility of effort $e_{n}$. Each agent is assumed to be effort averse: $G_{n}$ is strictly increasing in each component of $e_{n}$. The expected utility of agent $n$ is denoted by $U^{n}$.

The principal behaves as a Stackelberg leader to select a compensation scheme for each agent: She has the ability to commit herself to the scheme. Efforts are assumed to be unobservable to the principal while the outcome (or equivalently, the output) of each agent is publicly observable and contractible. Compensation schemes are hence contingent only on outcomes $(i, j) \in \Omega_{1} \times \Omega_{2}$. Let $w^{n}=\left(w_{i j}^{n}\right)$ be a payment scheme for agent $n$, where $w_{i j}^{n}$ is the payment to agent $n$ when output pair $\left(x_{i}^{1}, x_{j}^{2}\right)$ is realized. The principal is assumed to be risk neutral. Let $B_{i j}$ be the benefit of the principal from the output pair $\left(x_{i}^{1}, x_{j}^{2}\right)$ and $B\left(e_{1}, e_{2}\right)=\sum_{i} \sum_{j} P_{i j}\left(e_{1}, e_{2}\right) B_{i j}$ be the expected benefit. $B_{i j}$ is assumed to be strictly increasing in $i$ and $j$. The objective of the principal is to maximize the net profit, which is given by the expected benefit minus the expected payments to the agents $B\left(e_{1}, e_{2}\right)-\sum_{i} \sum_{j} P_{i j}\left(e_{1}, e_{2}\right)\left(w_{i j}^{1}+w_{i j}^{2}\right)$.

The coalition-free solution

As a benchmark, I first define the principal's problem when side contracting is infeasible. Following Grossman and Hart (1983), I decompose the principal's problem into two parts. In the first part, the principal fixes an effort pair $\left(e_{1}, e_{2}\right)$ and finds the compensation schemes which implement it with least costs. This problem is called the implementation problem for that effort pair. The solution to this problem defines the minimum expected cost of implementing $\left(e_{1}, e_{2}\right)$, denoted by $C\left(e_{1}, e_{2}\right)$. Once the implementation problem is solved for each effort pair, in the second part, the principal chooses the effort pair which maximizes her expected net profit $B\left(e_{1}, e_{2}\right)-C\left(e_{1}, e_{2}\right)$. It is sufficient to examine the implementation problem for most of the results in this paper. Throughout the paper, I only consider the implementation of the efforts which are not least costly, that is, $G_{n}\left(e_{n}\right)>\min _{e} G_{n}(e)$ for each $n$.

To define the implementation problem for $\left(e_{1}, e_{2}\right)$ formally, let $v_{i j}^{n}=V_{n}\left(w_{i j}^{n}\right)$, and $\phi_{n}$ be the inverse function of $V_{n}$. I sometimes call $v^{n}$ a compensation scheme for agent $n$, instead of $w^{n}$. Then the implementation problem in the absence of coalition, called (CF) which represents 
"coalition free," is defined as follows:

$$
\min _{v^{1}, v^{2}} \sum_{i} \sum_{j} P_{i j}\left(e_{1}, e_{2}\right)\left(\phi_{1}\left(v_{i j}^{1}\right)+\phi_{2}\left(v_{i j}^{2}\right)\right)
$$

subject to

$$
\begin{aligned}
& e_{1} \in \underset{e}{\arg \max } \sum_{i} \sum_{j} P_{i j}\left(e, e_{2}\right) v_{i j}^{1}-G_{1}(e) \\
& \text { (IC) } e_{2} \in \underset{e}{\arg \max } \sum_{i} \sum_{j} P_{i j}\left(e_{1}, e\right) v_{i j}^{2}-G_{2}(e) \\
& \text { (PC) } \quad \sum_{i} \sum_{j} P_{i j}\left(e_{1}, e_{2}\right) v_{i j}^{n}-G_{n}\left(e_{n}\right) \geq \bar{U}^{n} \quad \text { for } n=1,2 .
\end{aligned}
$$

The objective function in (CF) is the principal's expected payments to the agents. Constraints (IC), incentive compatibility constraints, imply that the agents select a Nash equilibrium effort pair of the simultaneous-move game of effort choice following the specification of compensation schemes by the principal. Constraints $(\mathrm{PC})$ are the participation constraints: the expected utility of agent $n$ must be at least as large as his reservation utility level $\bar{U}^{n}$. The solution to this problem is called the optimal coalition-free schemes.

\section{The coalition-proof solution}

I now introduce the possibility of coalition between two agents into the model. After accepting the contracts offered by the principal, but before outcomes are realized, the agents engage in side contracting contingent on publicly observable outcomes/outputs only. A side contract specifies monetary transfers $t=\left(t_{i j}\right)$ where $t_{i j}$ is the transfer from agent 1 to agent 2 when outcomes $(i, j)$ realize.

Suppose that a side contract is signed after the agents select their efforts independently. Whether a contract is signed before or after efforts are chosen does not actually matter. Given the effort pair $\left(e_{1}, e_{2}\right)$, they select a Pareto optimal side contract. That is, $t$ solves

$$
\begin{aligned}
& \max \sum_{i} \sum_{j} P_{i j}\left(e_{1}, e_{2}\right) V_{1}\left(w_{i j}^{1}-t_{i j}\right)-G_{1}\left(e_{1}\right) \\
& \text { subject to } \sum_{i} \sum_{j} P_{i j}\left(e_{1}, e_{2}\right) V_{2}\left(w_{i j}^{2}+t_{i j}\right)-G_{2}\left(e_{2}\right) \geq \hat{U}^{2}
\end{aligned}
$$

where $\hat{U}^{2}$ is the utility level guaranteed to agent 2 in the agreement between the agents. $\hat{U}^{2}$ could depend on $\left(e_{1}, e_{2}, w^{1}, w^{2}\right)$ as well as the technologies and the preferences of the agents. 
I only assume that $\hat{U}^{2} \geq \bar{U}^{2}$ : otherwise, agent 2 would not agree to form a coalition with agent 1 . The first-order condition yields the necessary and sufficient condition for the Pareto optimal transfers as follows: there exists $\lambda$ such that for each $(i, j)$,

$$
V_{1}^{\prime}\left(w_{i j}^{1}-t_{i j}\right)=\lambda V_{2}^{\prime}\left(w_{i j}^{2}+t_{i j}\right)
$$

where $\lambda$ is positive and possibly depends on $\left(e_{1}, e_{2}, w^{1}, w^{2}\right)$ and all the parameters of the model, as $\hat{U}^{2}$ does.

Note that transfers from agent 1 to agent 2 do not directly affect the principal's payments to them. The only effect of side transfers comes from the fact that they alter the effort choice game played by the agents: the agents will select the efforts based on their final incomes after side transfers rather than their compensation designed by the principal. How does the possibility of such a side contract between agents change the principal's welfare?

As Tirole (1986) pointed out in his model of principal/supervisor/agent relationships, the principal in our model can, without any loss, design the initial contract so as to prevent any further side contracting between agents. This is called the equivalent principle by Tirole: without loss of generality, the principal can limit herself to contracts which do not induce the agents to form a coalition, once the new constraint that the initial contract must attain the optimal mutual risk sharing between the agents is introduced. I call such contracts coalitionproof. By (2.1), coalition-proof compensation schemes $\left(v^{1}, v^{2}\right)$ have to satisfy the following coalition incentive compatibility constraints (CIC 1 ):

$$
\frac{1}{\phi_{1}^{\prime}\left(v_{i j}^{1}\right)}=\frac{\lambda}{\phi_{2}^{\prime}\left(v_{i j}^{2}\right)} \quad \text { for each }(i, j) \text {. }
$$

The principal's (implementation) problem for $\left(e_{1}, e_{2}\right)$, called (CP), is then defined as follow: ${ }^{7}$

$$
\begin{aligned}
& \min _{v^{1}, v^{2}} \sum_{i} \sum_{j} P_{i j}\left(e_{1}, e_{2}\right)\left(\phi_{1}\left(v_{i j}^{1}\right)+\phi_{2}\left(v_{i j}^{2}\right)\right) \\
& \text { subject to (IC), (PC), and (CIC 1). }
\end{aligned}
$$

The solution to this problem is called the optimal coalition-proof schemes. Note that since

${ }^{7}$ In problem (CP), it is implicitly assumed that positive $\lambda$ is chosen by the agents and the principal knows that value. The results shown below would not change even when the principal herself could select $\lambda$. 
efforts are mutually unobservable, each agent selects his effort independently despite the opportunity of side contracting. The following result is now immediate. ${ }^{8}$

THEOREM 1. When only outputs are mutually observable to the agents, the possibility of monetary side contracting between them contingent on their outputs never makes the principal better off.

The severity of constraints (CIC 1) can be illustrated most clearly in the case where the optimal coalition-free compensation scheme for an agent is independent of the other agent's output. Such a scheme is called an individual-based scheme. It is immediate to conclude that individual-based schemes cannot satisfy (CIC 1) unless either $e_{1}$ or $e_{2}$ is the least costly effort (which case is excluded by assumption). To see this, suppose that there is no production externality and that the noise terms are stochastically independent. It is well known in the literature of relative performance evaluation (e.g., Holmström, 1982; Mookherjee, 1984) that in such a case the optimal coalition-free contract is individual-based. If $e_{1}$ is not the least costly effort, the optimal individual-based scheme for agent 1 is not flat. Then (CIC 1) imply that any coalition-proof compensation for agent 2 must depend on the output of agent 1 , so that it cannot be an individual-based scheme.

COROllary 1. Individual-based incentive schemes are not coalition-proof.

Theorem 1 implies that when agents' efforts are unobservable to each other, their coalition through monetary side contracting is never beneficial to the principal. Another way of stating this result, as Holmstrom and Milgrom (1990) and Varian (1989) emphasize, is that in order for coalition among agents to be of value to the principal, it is necessary that the agents share some information unobservable to her. In the subsequent sections, I assume that the agents can monitor each other's effort, so that the efforts are contractible between the agents.

\section{Mutual Monitoring in Effort Choice: Case of Independence}

I hereafter assume that each agent can observe the other agent's choice of effort. This implies that the agents can write a (enforceable) side contract contingent on their effort choice

8 The same result is independently presented in Holmstrom and Milgrom (1990), Ramakrishnan and Thakor (1990), and Varian (1989). 
as well as their outputs. As a result of such side contracting, they can enforce a Pareto optimal effort pair. ${ }^{9}$ The question is whether such a coalition improves the principal's welfare.

Contrary to the case of side contracting without mutual monitoring, it may not be in the principal's interest to prevent further side contracting when mutual monitoring is possible. The reason is that she may prefer the agents to coordinate their effort choice via side contracts. The following approach is thus taken. I first formulate the principal's (implementation) problem for a given effort pair $\left(e_{1}, e_{2}\right)$ under the assumption that the agents side contract on their efforts as well. She designs the initial contract so as to implement $\left(e_{1}, e_{2}\right)$ as a Pareto optimal effort pair agreed upon by the agents in their coordination process. However, she prevents any other side transfer contingent on outputs. Side transfers hence do not occur as long as the agents select the effort pair they agreed on. This problem is called (EC), representing "effort coordination." I then compare this problem with the principal's problem (CF) for coalition-free contracts. If there exist feasible compensation schemes for problem (EC) which can implement $\left(e_{1}, e_{2}\right)$ with lower costs than the solution to $(\mathrm{CF})$, then I can conclude that the principal is better off under side contracting between the agents than under no side contracting.

In problem (EC), the incentive compatibility constraints (IC) are replaced by the following two coalitional incentive compatibility constraints (CIC 2) and (CIC 3):

$$
\begin{aligned}
\left(e_{1}, e_{2}\right) \in \underset{e_{1}^{\prime}, e_{2}^{\prime}}{\arg \max } \sum_{i} & \sum_{j} P_{i j}\left(e_{1}^{\prime}, e_{2}^{\prime}\right) v_{i j}^{1}-G_{1}\left(e_{1}^{\prime}\right) \\
& \text { subject to } \sum_{i} \sum_{j} P_{i j}\left(e_{1}^{\prime}, e_{2}^{\prime}\right) v_{i j}^{2}-G_{2}\left(e_{2}^{\prime}\right) \geq \hat{U}^{2}
\end{aligned}
$$

$$
\sum_{i} \sum_{j} P_{i j}\left(e_{1}, e_{2}\right) v_{i j}^{n}-G_{n}\left(e_{n}\right) \geq \sum_{i} \sum_{j} P_{i j}\left(e^{N}(v)\right) v_{i j}^{n}-G_{n}\left(e_{n}^{N}(v)\right) \text { for } n=1,2
$$

where $e^{N}(v)=\left(e_{1}^{N}(v), e_{2}^{N}(v)\right)$ is a Nash equilibrium effort pair under the schedule $v=\left(v^{1}, v^{2}\right)$. Constraint ( $\mathrm{CIC} 2)$ implies that the agents enforce $\left(e_{1}, e_{2}\right)$ specified by the principal as a Pareto optimal effort pair through side contracting. Constraints (CIC 3) imply that each agent is in fact better off by coordinating their effort choice than by selecting the efforts independently. If (CIC 3) did not hold, they would not be able to reach agreement on the effort choice in their coordination process.

9 As I discussed in Introduction, the enforcement problem is assumed away. However, see Section 8 for an informal discussion concerning enforcement mechanisms. 
The principal's problem (EC) for a given effort pair $\left(e_{1}, e_{2}\right)$ is then defined as follows:

$$
\begin{aligned}
& \min _{v^{1}, v^{2}} \sum_{i} \sum_{j} P_{i j}\left(e_{1}, e_{2}\right)\left(\phi_{1}\left(v_{i j}^{1}\right)+\phi_{2}\left(v_{i j}^{2}\right)\right) \\
& \text { subject to (PC), (CIC 1), (CIC 2), and (CIC } 3) .
\end{aligned}
$$

Under any compensation schemes satisfying all the constraints in problem (EC), the agents have no incentive to exercise the side contract as long as they have selected the Pareto optimal effort pair. They engage in side contracting only to enforce their coordinated effort choice. And they in fact prefer to do so because of (CIC 3).

There are several remarks on problem (EC). First, note that in the general framework presented here I do not assume the existence of transferable utility. ${ }^{10}$ If utility is transferable, (PC) and (CIC 2) are simplified as follows:

$$
\begin{aligned}
& \sum_{i} \sum_{j} P_{i j}\left(e_{1}, e_{2}\right)\left(v_{i j}^{1}+v_{i j}^{2}\right)-G_{1}\left(e_{1}\right)-G\left(e_{2}\right) \geq \bar{U}^{1}+\bar{U}^{2} \\
& \left(e_{1}, e_{2}\right) \in \underset{e_{1}^{\prime}, e_{2}^{\prime}}{\arg \max } \sum_{i} \sum_{j} P_{i j}\left(e_{1}^{\prime}, e_{2}^{\prime}\right)\left(v_{i j}^{1}+v_{i j}^{2}\right)-G_{1}\left(e_{1}^{\prime}\right)-G_{2}\left(e_{2}^{\prime}\right) ;
\end{aligned}
$$

Similarly, constraint (CIC 3) will be replaced by the weaker constraint that the sum of the agents' expected utilities is as high as the sum of the expected utilities under their noncooperative effort choice. However, (CIC 3), when modified in such a way, is then always satisfied by definition. The existence of transferable utility is beneficial to the principal, particularly when the agents are not homogeneous, because then she will not need to worry about payoff allocation between the agents, as we will see later in this section.

Second, I have not substituted first-order conditions for (CIC 2) as we did for (CIC 1). Additional conditions are required to ensure that the first-order conditions are necessary and sufficient. In fact, the main result in this section presented below does not rely on the "firstorder approach."

Third, in problem (EC), it is implicitly assumed that $\hat{U}^{2}$ and $\lambda$ are determined by the agents and the principal knows those values. Below, I show that somehow surprisingly, whether

10 Utility is transferable if there exists a good such that the utility of agent $n$ who possesses $z_{n}$ amounts of the good is given by $V_{n}(w)-G_{n}\left(e_{n}\right)+z_{n}$. 
or not the principal knows how the agents reach an agreement, she can direct them to particular $\hat{U}^{2}$ and $\lambda$ and enforce those values on the agents who accept the initial contracts: the agents, once they accept the contracts offered by the principal, can in no way agree on a bargaining solution different from what has been specified by the principal in the initial contracts.

In this section, I analyze the case where the optimal contracts consist of individual-based schemes in the absence of coalition. Sufficient conditions for this to be true is that there is no production externality (production functions are separable in effort) and the noise terms are stochastically independent. Although the independence of noise terms is not necessary for independent schemes to be optimal (Mookherjee, 1984), both conditions are assumed throughout this section for simplicity. Thus, $P_{i j}\left(e_{1}, e_{2}\right)=P_{i}^{1}\left(e_{1}\right) P_{j}^{2}\left(e_{2}\right)$ for each $(i, j)$, given $\left(e_{1}, e_{2}\right)$. All the results presented in this section hold when the noise terms are correlated, so long as the optimal coalition-free schemes are individual-based.

\section{Case of homogeneous agents}

I first consider the case where the agents are symmetric in preferences and production functions. More precisely, I assume: (a-i) two agents have the same utility-on-income function $V ;($ a-ii) they have the same disutility function $G$ and the same reservation utility level $\bar{U}$; (a-iii) they have identical production technology so as to have the same probability $P_{i}(e)$ of output $x_{i}$ for each outcome $i \in \Omega=\{1, \ldots, I\}$ and each effort $e$; and (a-iv) their outputs are equally valued so that $B_{i j}=B_{j i}$ for each $i, j \in \Omega$. Under assumptions (a-i)-(a-iv), there is a symmetric effort pair $(e, e)$ which is the second-best (in the absence of coalition).

Let $v^{n}=\left(v_{i}^{n}\right)$ be the optimal coalition-free compensation scheme for agent $n$. By symmetry, $v_{i}^{1}=v_{j}^{2}$ if $i=j$. Before presenting the general result, consider an example of two possible outcomes $\Omega=\{L, H\}$ with $x_{L}<x_{H}$. Let $p(e)=P_{H}(e)$ be increasing in each component of $e$. The optimal coalition-free scheme implementing effort $e$ for each agent (which I have assumed is not least costly) satisfies $v_{L}^{n}<v_{H}^{n}$. Define the new interdependent schedule $\left(\hat{v}^{1}, \hat{v}^{2}\right)$ by

$$
\hat{v}_{i j}^{1}=\hat{v}_{i j}^{2}=\frac{1}{2} v_{i}^{1}+\frac{1}{2} v_{j}^{2}
$$

for each $i, j=L, H$. Under the original individual-based contract, agent $n$ faces the following lottery; the higher wage $v_{H}^{n}$ with probability $p(e)$ and the lower wage $v_{L}^{n}$ with probability $1-p(e)$. Under the new interdependent scheme, the lottery changes to; $v_{H}^{n}$ with probability 
$(p(e))^{2}, v_{L}^{n}$ with probability $(1-p(e))^{2}$, and $\frac{1}{2}\left(v_{H}^{n}+v_{L}^{n}\right)$ with probability $2 p(e)(1-p(e))$. Note that each agent is paid higher compensation as the outcome of the other agent is better.

The new schemes satisfy constraints (CIC 1) when $\lambda=1$ since the agents are paid an equal amount of compensation in each outcome pair $(i, j)$. And if the agents forming a coalition agree to select the given effort pair $(e, e)$ under the new schemes as well, the principal's expected payments to the agents will be reduced by adopting $\left(\hat{v}^{1}, \hat{v}^{2}\right)$ because less risk is imposed on them.

In the absence of the coordination in effort choice by the agents, the new interdependent schemes weaken each agent's effort incentives since the marginal utility on income with respect to his effort is now half of that under the original independent scheme. However, when the agents can monitor each other's efforts and contract on them, this loss in incentives can be avoided: I show in the next theorem that the interdependent schemes constructed above induce the agents to select the same effort $e$ when they side contract. The theorem consists of two parts. First, I prove this result supposing that the principal can select $\hat{U}^{2}$ and $\lambda$ and the agents follow her direction. Then, it is shown that the agents, once they accept the initial contracts, cannot agree on $\left(\hat{U}^{2}, \lambda\right)$ other than those in the initial contracts, because one of the agents must suffer from the expected utility lower than his reservation level in other solutions. ${ }^{11}$

THEOREM 2. The following hold under the assumptions given above: (a) If the principal can choose $\left(\hat{U}^{2}, \lambda\right)$, she can implement any given symmetric effort pair $(e, e)$ with less costs under side contracting on efforts than under no side contracting; (b) The agents, once they accept the initial contracts, cannot agree to attain a Pareto optimal utility pair different from what the principal specified in the initial contracts.

Proof: Suppose that $\left(v_{i}^{1}\right)$ and $\left(v_{j}^{2}\right)$ are the optimal coalition-free schemes for a given effort $e$, which are symmetric in the sense of $v_{i}^{1}=v_{j}^{2}$ if $i=j$. Define the new schemes $\left(\hat{v}_{i j}^{1}, \hat{v}_{i j}^{2}\right)$ by (3.1) for each $i$ and $j$. Part (a): Simple calculation shows that $\left(\hat{v}^{1}, \hat{v}^{2}\right)$ satisfies (PC) and (CIC 3 ) for each agent, because of symmetry. Concerning (CIC 2), by definition, $\hat{v}_{i j}^{1}+\hat{v}_{i j}^{2}=v_{i}^{1}+v_{j}^{2}$ for each $(i, j)$. Thus, $(e, e)$ maximizes the sum of the agents' expected utilities under the

11 A special version of the theorem was first proved in Itoh (1988). Recently Holmstrom and Milgrom (1990) prove a similar result in the linear model developed by Holmstrom and Milgrom (1987). Related results are found in Macho-Stadler and Pérez-Castrillo (1990) and Ramakrishnan and Thakor (1990) in which a specific form of production externality is assumed, as is mentioned in Section 6. 
new schemes, which is equal to $\left(\sum_{i} P_{i}\left(e_{1}\right) v_{i}^{1}-G\left(e_{1}\right)\right)+\left(\sum_{j} P_{j}\left(e_{2}\right) v_{j}^{2}-G\left(e_{2}\right)\right)$, because $e$ maximizes each agent's expected utility under the original scheme. Let $\hat{U}^{2}$ be defined by $\hat{U}^{2}=\sum_{i} \sum_{j} P_{i j}(e, e) \hat{v}_{i j}^{2}-G(e)$. Then $(e, e)$ satisfies (CIC 2), and the expected utility of agent 1 is also equal to $\hat{U}^{2}$ by symmetry. Then $\left(\hat{v}^{1}, \hat{v}^{2}\right)$ satisfies (CIC 1 ) for each $(i, j)$ with $\lambda=1$ because the agents are paid equally in each pair of outcome. As the last step, one can easily show that by Jensen's inequality, the expected wage payments of the principal are strictly smaller under the new schemes than under the original individual-based schemes.

To show Part (b), note that the optimal coalition-free scheme gives each agent exactly his reservation utility level. Thus, $\hat{U}^{2}$ defined above is equal to $\bar{U}$ and hence each agent attains exactly $\bar{U}$ under the new schemes. Thus, after accepting the initial contracts, if the agents attempt to choose a different point on the Pareto frontier, one of them must suffer from the expected utility lower than the reservation level, and hence cannot agree on such a point. Therefore, they must follow the direction specified by the principal.

Q.E.D.

The intuition of the result goes as follows. Effort coordination enables the principal to improve risk sharing between her and each of the homogeneous agents by designing an interdependent schedule for them, without weakening their incentives to select a given effort pair. Side contracting with mutual monitoring is thus beneficial to the principal. Note that the principal is better off under coalition not because the agents can share risk between them, but because they can monitor each other's effort and coordinate their choice of efforts. We have already seen that mutual risk sharing only never makes the principal better off. It is also easy to observe that Theorem 2 holds without the possibility of mutual insurance. Suppose that monetary side transfers are impossible (e.g., because they are conspicuous) so that mutual risk sharing is unavailable between the agents, while they can coordinate their efforts through some nonpecuniary transfers like the norm of reciprocity. Such a modification does not change the conclusion of Theorem 2 at all. ${ }^{12}$

Case of asymmetry: example of constant absolute risk aversion

I next assume that agent $n$ has the utility function with constant absolute risk aversion $r_{n}: V_{n}(w)=-\exp \left(-r_{n} w\right)$ for $w \geq 0$. With this specification, constraints (CIC 1$)$ can be

12 On the other hand, Varian (1989) suggests that the principal possibly realizes the benefits from mutual insurance between agents if their private information is exogenous information (about the state of nature), instead of endogenous information (about discretionary actions). (These terms are by de Groote (1988).) 
rewritten as follows:

$$
\frac{\hat{v}_{i j}^{1}}{\hat{v}_{i j}^{2}}=\lambda \frac{r_{2}}{r_{1}} \quad \text { for each }(i, j) .
$$

If utility is transferable, it is easily shown that the result presented above is extended to this asymmetric case. Because of the existence of transferable utility, (PC) and (CIC 2) are simplified as (TPC) and (TCIC 2). Note, however, that the existence of transferable utility does not change their incentives for mutual insurance via monetary side transfers. I define $\left(\hat{v}^{1}, \hat{v}^{2}\right)$, satisfying $(3.2)$ with $\lambda=1$, as follows: for each $(i, j)$,

$$
\begin{aligned}
& \hat{v}_{i j}^{1}=\frac{r_{2}}{r}\left(v_{i}^{1}+v_{j}^{2}\right) \\
& \hat{v}_{i j}^{2}=\frac{r_{1}}{r}\left(v_{i}^{1}+v_{j}^{2}\right)
\end{aligned}
$$

where $\left(v^{1}, v^{2}\right)$ is the optimal contracts implementing a given effort pair $\left(e_{1}, e_{2}\right)$ in the absence of coalition. Then for each $(i, j), \hat{v}_{i j}^{1}+\hat{v}_{i j}^{2}=v_{i}^{1}+v_{j}^{2}$. Thus, the agents select $\left(e_{1}, e_{2}\right)$ under the new schemes, and hence (TCIC 2) is satisfied. Similarly, the sum of the agents' expected utilities is equal to $\bar{U}^{1}+\bar{U}^{2}$. Finally, straightforward calculation shows that the principal's expected payments are smaller under the new schedule than under the original schedule.

When utility is not transferable, the extension of the result to the asymmetric case is more complicated because the principal must care about payoff allocation between the agents. For simplicity, suppose that (CIC 2) can be replaced by the first-order condition with the same $\lambda$ as in (CIC 1). The principal can still elicit a given effort pair from the effort-coordinating agents with less costs and give them exactly their reservation utility levels. She can do so by giving more bargaining power to agent $2(\lambda>1)$ when he is less risk averse, has better outside options, or incurs higher disutility of work than agent 1 . However, then agent 1 might find it in his interest not to cooperate with agent 2 but to behave independently because the effort choice of agent 2 tends to be less sensitive to whether agent 1 plays the coordinated effort or behaves independently. Therefore, the principal might have to give agent 1 an expected utility level higher than his reservation level. Because we have seen in Theorem 2 that this does not happen for homogeneous agents, ${ }^{13}$ the result in the symmetric case will still hold as long as the extent of asymmetry is sufficiently small.

13 Note that Theorem 2 does not assume the existence of transferable utility. 
Effort coordination is of no value under individual-based schemes

One important implication from the analysis in this section is that individual-based incentive schemes cannot be optimal when the agents coordinate their effort choice, even if they do not share risk between them. Although I do not solve problem (EC) for the optimal schedule, it is clear that under individual-based schemes, the expected utility of each agent is independent of the effort of the other agent, and hence the agents' effort choice is not affected by whether they coordinate efforts or not. Thus, side contracting on efforts has no value under individual-based incentive schemes. Some forms of interdependent schemes, under which an agent's compensation is contingent on the performance of the other agent as well, are necessary for effort coordination to be of value to the principal.

COROLLARY 2. When no production externality exists, effort coordination by agents is of no value to the principal under individual-based incentive schemes.

\section{Mutual Monitoring in Effort Choice: Team Production}

In this section and the following two sections, I extend the analysis in the preceding section to cases in which each agent's welfare is interdependent on the other agent's effort under the optimal coalition-free schemes. Such a case applies (i) when there is team production so that the output of each individual agent is unobservable; (ii) when there exist production externalities, such as "help," and hence the optimal coalition-free contract pays an agent higher remuneration the better the performance of the other agent is; (iii) when no production externality exists, yet there exist systematic risks so that noise terms are (positively) correlated and relative performance evaluation is optimal. This section deals with the case of team production. Then in the next section, I consider a model of effort allocation among tasks as an example of production externalities. I show that the conclusion in the previous section (the benefits of effort coalition) can still hold in cases (i) and (ii) under some strong conditions. Important distinction of these two cases from case (iii) is then discussed in Section 6 .

Let me modify the model introduced in Section 2 such that the principal cannot observe the output of each agent separately but aggregate output is contractible. Suppose that there are $I$ possible total output levels $x_{1}<\cdots<x_{I}$ and let $\Omega=\{1, \ldots, I\}$ be the set of outcomes. Total output is determined by efforts exerted by two agents and a noise term. Let $P_{i}\left(e_{1}, e_{2}\right)$ 
be the probability of $x=x_{i}$ when $\left(e_{1}, e_{2}\right)$ is chosen by the agents. The benefit from output $x_{i}$ is written as $B_{i}$, which is strictly increasing in $i$, and the expected benefit of the principal is now defined by $B\left(e_{1}, e_{2}\right)=\sum_{i} P_{i}\left(e_{1}, e_{2}\right) B_{i}$. Other definitions are accordingly modified as well.

To simplify the exposition, hereafter in this section, I assume that the effort variable is one-dimensional, and moreover, $I=2$ and $\Omega=\{L, H\}$. The results presented in this section continue to hold for the more general case of $I>2$.

I first consider the case in which the "first-order approach" is valid. Let $p\left(e_{1}, e_{2}\right)$ be the probability that output is $x_{H}$, and suppose that $p(\cdot)$ is twice continuously differentiable and strictly increasing in $e_{n}$ for $n=1,2$. This second assumption implies that $p(\cdot)$ satisfies strict monotone likelihood ratio property (strict MLRP). Also suppose that $G_{n}(\cdot)$ is twice continuously differentiable and strictly convex. Then if $p(\cdot)$ also satisfies convexity of the distribution function condition (CDFC), that is, $p(\cdot)$ is concave in $e_{n}$ for each $n$, then the first-order approach is valid: the incentive compatibility constraints (IC) in the absence of coalition can be replaced by the first-order conditions, and the optimal coalition-free incentive schemes $\left(v^{1}, v^{2}\right)$ are monotone increasing $\left(v_{H}^{n}>v_{L}^{n}\right)$. See Rogerson (1985) for the proof.

The next theorem is a counterpart of Theorem 2 in this team context. Although I am simplifying the statement, the theorem consists of the same two parts as those in Theorem 2. In the theorem, the homogeneity of the agents is defined by (a-i) and (a-ii) in the previous section, and instead of (a-iii), by the following assumption: the agents have an identical production technology so that for each $i, P_{i}$ is exchangeable, that is, $P_{i}\left(e_{1}, e_{2}\right)=P_{i}\left(e_{2}, e_{1}\right)$. The proof is in Appendix.

THEOREM 3. Under the assumptions given above, if $p(\cdot)$ is convex in $\left(e_{1}, e_{2}\right)$ and the agents are homogeneous, the principal can implement any symmetric effort pair with less costs under side contracting on efforts than under no side contracting.

Because of symmetry, the optimal coalition-free compensation schedule for a symmetric effort pair $(e, e)$ pays each agent an equal compensation $v_{i}$ in each outcome $i$. Then in the proof, a new scheme is defined by $\hat{v}_{i}=\frac{1}{2} v_{i}+\frac{1}{2}(\bar{U}+G(e))$. The new scheme reduces the variation of compensation (in utility units) to half of that under the original scheme so as to satisfy the other constraints. This reduction of risk does not alter the agents' incentive to 
select a given effort pair when they side contract on efforts. And the principal's payments are lower because of the improvement in risk sharing.

The role of the conditions in the theorem is to ensure that $(e, e)$ satisfies (CIC 2). The effort pair $(e, e)$ is a Nash equilibrium under $\left(v_{i}\right)$ so that it is a person-by-person optimal effort pair for problem (CIC 2). However, this does not generally imply that $(e, e)$ is the overall optimal effort pair. The conditions given above, the convexity of $p(\cdot)$ which is stronger than CDFC, is sufficient for the person-by-person optimum to be globally optimal, as Marschak and Radner (1972) and Radner (1962) showed. ${ }^{14}$

Another sufficient condition, though obvious, is that $(e, e)$ is the unique Nash equilibrium under the optimal coalition-free schemes. Unfortunately, this is not usually the case. As Demski and Sappington (1984) and Mookherjee (1984) showed, there often exists another equilibrium preferred by all the agents to the one the principal wishes to implement. And we do not know sufficient conditions for the uniqueness.

If there exist multiple equilibria under the optimal coalition-free contracts, the benchmark problem (CF) of implementing a given effort pair must be examined more carefully. This multiple equilibrium problem does not cause any trouble in the absence of coalition, if, for example, the effort pair the principal wants to implement is the one most preferred by all the agents among equilibrium efforts. However, the following example shows that the existence of multiple equilibria could dissipate the benefits of effort coalition even in such a case.

Example. Suppose that each agent has finite feasible effort levels $e^{1}<\cdots<e^{K}$. The probability that $H$ realizes is assumed to depend only on the minimum of agent 1's effort and agent 2's (i.e., the efforts are perfect complements). Let $p^{k}$ be the probability of $H$ when the minimum of $e_{1}$ and $e_{2}$ is $e^{k}$, with $p^{1}<\cdots<p^{K}$. The disutility of effort $e^{k}$ is denoted by $g^{k}=G\left(e^{k}\right)$ which is increasing in $k$. Let $f^{k}=\left(g^{k}-g^{k-1}\right) /\left(p^{k}-p^{k-1}\right)$ for $k \geq 2$. Assume that there exist "decreasing returns to effort," that is,

$$
f^{2}<\cdots<f^{K}
$$

Fix $k>1$ and consider the implementation problem of the symmetric effort pair $\left(e^{k}, e^{k}\right)$. (The second-best effort pair is clearly symmetric in this example.) When coalition is infeasible, the optimal coalition-free schemes $\left(v_{L}^{k}, v_{H}^{k}\right)$ satisfy

$$
v_{H}^{k}-v_{L}^{k}=f^{k} .
$$

14 The validity of the first-order approach is also a part of the sufficient conditions in their results as the person-by-person optimal actions are assumed to satisfy first-order conditions. 
It is easy to see this because each agent has no incentive to increase his effort unilaterally, and by $(*)$, the incentive compatibility constraints are binding only for the constraint that each agent does not deviate to the next lower effort $e^{k-1}$. Then it can be easily shown that under $\left(v_{L}^{k}, v_{H}^{k}\right),\left(e^{1}, e^{1}\right), \ldots,\left(e^{k}, e^{k}\right)$ are all Nash equilibria. However, since each agent's expected utility under $\left(e^{k}, e^{k}\right)$ (which the principal wishes to implement) is at least as high as his expected utility under any other equilibrium, the existence of multiple equilibria does not cause a serious problem in implementing $\left(e^{k}, e^{k}\right)$.

Next, consider the case of effort coordination. Can the principal find a new schedule $\left(\hat{v}_{L}^{k}, \hat{v}_{H}^{k}\right)$ which implements $\left(e^{k}, e^{k}\right)$ with less risk imposed on the agents $\left(\hat{v}_{H}^{k}-\hat{v}_{L}^{k}<f^{k}\right)$ ? The answer is no, since if risk is reduced from $f^{k}$, then the agents strictly prefer choosing $\left(e^{k-1}, e^{k-1}\right)$ to $\left(e^{k}, e^{k}\right)$. Thus, in this example, effort coordination does not yield any extra benefit to the principal.

In the example, the assumption of strong complementarity between the efforts makes the reduction of risk under effort coordination infeasible. The next theorem shows that if such a complementarity does not exist, then a given symmetric effort pair, when it is the most preferred equilibrium for both agents under the optimal coalition-free contracts, can be implemented with less costs under coalition with mutual monitoring of efforts than under no coalition. In the theorem, a Nash equilibrium $\left(e_{1}, e_{2}\right)$ is called dominant if there exists no other equilibrium that at least one agent strictly prefers to $\left(e_{1}, e_{2}\right)$. Note that this condition is stronger than undominated Nash equilibrium. Two conditions coincide if there only exist symmetric equilibria.

TheOrem 4. Assume that the agents are homogeneous, and for $e_{n}>e_{n}^{\prime}, n=1,2$,

$$
p\left(e_{1}, e_{2}^{\prime}\right)-p\left(e_{1}^{\prime}, e_{2}^{\prime}\right) \geq p\left(e_{1}, e_{2}\right)-p\left(e_{1}^{\prime}, e_{2}\right)
$$

Then if $(e, e)$ is a dominant Nash equilibrium under the optimal coalition-free schemes, the principal can implement $(e, e)$ with less costs under side contracting on efforts than under no side contracting.

See Appendix for the proof. ${ }^{15}$ Condition (4.1) implies that increasing the effort of an agent reduces the return to increasing the other agent's effort. In this sense, it involves substitutabilities rather than complementarities. Mathematically, the condition is equivalent

15 Note that this result does not depend on the validity of the first-order approach. 
to $p(\cdot)$ being submodular when $e_{n}$ is chosen from a closed subset of the real line. Observe that (4.1) does not hold in Example. When the efforts are complements, the agents are tempted to simultaneously increase or decrease from a given symmetric effort pair. Thus, lowering the risk imposed on the agents could induce them to deviate to another Nash equilibrium effort pair when they coordinate their efforts.

One caveat: The assumption of homogeneous agents throughout this section is not innocuous. For simplicity, suppose that transferable utility exists. Then if the assumptions in Theorem 3 except for the homogeneity of the agents hold, the coordinated efforts chosen by them satisfy the following first-order conditions (assuming interior solution) for (TCIC 2):

$$
\begin{aligned}
& p_{1}\left(e_{1}, e_{2}\right)\left[\left(v_{H}^{1}-v_{L}^{1}\right)+\left(v_{H}^{2}-v_{L}^{2}\right)\right]=G_{1}^{\prime}\left(e_{1}\right) \\
& p_{2}\left(e_{1}, e_{2}\right)\left[\left(v_{H}^{1}-v_{L}^{1}\right)+\left(v_{H}^{2}-v_{L}^{2}\right)\right]=G_{2}^{\prime}\left(e_{2}\right)
\end{aligned}
$$

where $p_{n}(\cdot)$ is the derivative of probability of $x=x_{H}$ with regard to $e_{n}$. These conditions yield the following:

THEOREM 5. Under the assumptions given above, the principal can implement $\left(e_{1}, e_{2}\right)$ under side contracting on efforts if and only if the effort pair satisfies

$$
\frac{p_{1}\left(e_{1}, e_{2}\right)}{p_{2}\left(e_{1}, e_{2}\right)}=\frac{G_{1}^{\prime}\left(e_{1}\right)}{G_{2}^{\prime}\left(e_{2}\right)}
$$

Condition (4.2) in the theorem implies a sort of efficiency in effort allocation: The effort pair $\left(e_{1}, e_{2}\right)$ satisfying (4.2) maximizes the probability of the total output being $x_{H}$ subject to the sum of the agents' disutilities being constant at some level. The theorem implies that the principal loses some control over the agents' effort allocation within a team; when they coordinate their efforts for themselves. The benefit of side contracting on efforts is therefore ambiguous. Since the second-best effort pair (under no coalition) does not necessarily satisfy condition (4.2), the analysis of implementation problems is not sufficient to determine whether or not mutual monitoring by agents benefits the principal. The principal's overall problem, including the choice of the optimal effort pair, must be examined, while the analysis of general agency models has little to say about the optimal second-best efforts. The case of homogeneous agents is special in the sense that the second-best effort pair in the coalition-free world satisfies (4.2) and hence the benefit of effort coordination realizes as is shown in Theorem 3. 
Of course, the point made here is not that the benefit from effort coordination is an exception under team production. What is shown is that the principal may implement different efforts under the two regimes compared here. Because effort coordination is strictly better than no coordination when agents are homogeneous, the relative advantage of the case of effort coordination will continue to hold for heterogeneous agents, so long as they are sufficiently homogeneous.

\section{Mutual Monitoring in Effort Choice: Effort Allocation}

I next consider a specific form of production externalities as analyzed in Itoh (1991a). Throughout this section, the agents are assumed to be homogeneous so that (a-i)-(a-iv) hold with appropriate modifications. Effort variable $e_{n}$ has the following specific form: Each agent chooses a two-dimensional effort vector $e_{n}=\left(a_{n}, b_{n}\right) \in[0, A] \times[0, B]$ with $A>0$ and $B>0$. The first element $a_{n}$, called his own effort, affects his output. The second element $b_{n}$ is called his helping effort which affects the other agent's output. Suppose that the error terms are stochastically independent so that the joint probability of $\left(x^{1}, x^{2}\right)=\left(x_{i}, x_{j}\right)$ is now written as $P_{i j}\left(e_{1}, e_{2}\right)=P_{i}\left(a_{1}, b_{2}\right) P_{j}\left(a_{2}, b_{1}\right)$. The disutility of each agent is a function of his own effort and his helping effort.

The purpose of this section is to show that restriction on the principal's control over the agents' coordinated effort choice is more severe here than the case of team production: I show that even though the agents are homogeneous, the principal cannot implement all the symmetric effort pair under effort coordination. As in the previous section, I assume $\Omega=\{L, H\}$ with $x_{H}>x_{L}$. Let $p\left(a_{n}, b_{k}\right)$ be the probability that output of agent $n$ is $x_{H}$. This is the probability of "success" of agent $n$ while $1-p\left(a_{n}, b_{k}\right)$ is the probability of "failure." It is assumed that $p(a, b)$ is strictly increasing in $a$ and $b$ : both own effort and helping effort are productive, and strict MLRP holds.

This section utilizes the first-order approach. Suppose that $p$ and $G$ are twice-continuously differentiable, $G$ is strictly convex, $P_{L L}$ is convex in $e_{n}$ for each $n$, and $\phi^{\prime}$ is convex. Itoh (1991a) shows that these assumptions are sufficient for the first-order approach to be valid. The convexity of $\phi^{\prime}$ holds when the coefficient of absolute risk aversion is increasing, constant, or decreasing relatively slowly in income. Utility functions which are frequently used in examples, such as exponential, logarithmic, or square root, satisfy this condition. Furthermore, I show in 
Itoh (1991a) that under the assumptions stated above, for $a>0$, (i) the optimal coalition-free scheme for $(a, 0)$ for each agent is individual-based, satisfying $v_{H}^{n}>v_{L}^{n}$; and (ii) the optimal scheme for $(a, b)$ with $b>0$ for each agent satisfies $v_{i H}^{n}>v_{i L}^{n}$ and $v_{H i}^{n}>v_{L i}^{n}$ for $i=L, H$. Note that by symmetry, $v_{i j}^{1}=v_{j i}^{2}$ for $i, j=L, H$.

I further assume that $P_{L L}$ is convex in $\left(e_{1}, e_{2}\right)$. As in Theorem 3 , this ensures that personby-person optimal effort pairs are also globally optimal when the agents coordinate their effort choice. This assumption also implies that $p(e)$ is concave in $e$.

Suppose that the principal wants to implement effort $e=(a, b)$ with $0<a<A$ and $0<b<B$ for each agent ${ }^{16}$ The first-order conditions for $(e, e)$ when the agents do not side contract are given as follows:

$$
\begin{aligned}
& p_{a}(e)\left[\left(v_{H L}^{1}-v_{L L}^{1}\right)+p(e) \Delta\right]=G_{a}(e) \\
& p_{b}(e)\left[\left(v_{L H}^{1}-v_{L L}^{1}\right)+p(e) \Delta\right]=G_{b}(e) \\
& p_{a}(e)\left[\left(v_{L H}^{2}-v_{L L}^{2}\right)+p(e) \Delta\right]=G_{a}(e) \\
& p_{b}(e)\left[\left(v_{H L}^{2}-v_{L L}^{2}\right)+p(e) \Delta\right]=G_{b}(e)
\end{aligned}
$$

where $\Delta=v_{H H}^{n}+v_{L L}^{n}-v_{H L}^{n}-v_{L H}^{n}$ and the subscripts for $p$ and $G$ represent partial derivatives.

When the agents side contract on efforts, the first-order conditions for $(e, e)$ under schedule $\left(\hat{v}^{1}, \hat{v}^{2}\right)$ are, assuming the existence of transferable utility, given as follows:

$$
\begin{aligned}
& p_{a}(e)\left[\left(\hat{v}_{H L}^{1}-\hat{v}_{L L}^{1}\right)+p(e) \hat{\Delta}+\left(\hat{v}_{H L}^{2}-\hat{v}_{L L}^{2}\right)+p(e) \hat{\Delta}\right]=G_{a}(e) \\
& p_{b}(e)\left[\left(\hat{v}_{L H}^{1}-\hat{v}_{L L}^{1}\right)+p(e) \hat{\Delta}+\left(\hat{v}_{L H}^{2}-\hat{v}_{L L}^{2}\right)+p(e) \hat{\Delta}\right]=G_{b}(e)
\end{aligned}
$$

where $\hat{\Delta}=\hat{v}_{H H}^{n}+\hat{v}_{L L}^{n}-\hat{v}_{H L}^{n}-\hat{v}_{L H}^{n}$. From (5.1) and (5.2) the following results hold. ${ }^{17}$

THEOREM 6. Under the assumptions given above, (a) when the agents coordinate their effort choice via side contracting, the principal can implement e for each agent if and only if

$$
\frac{p_{b}(e)}{p_{a}(e)}=\frac{G_{b}(e)}{G_{a}(e)}
$$

16 A sufficient condition for the second-best effort to have positive help is given in Itoh (1991a). I present such an example later in this section.

17 Macho-Stadler and Pérez-Castrillo (1990) also show a result similar to part (b) in the theorem. 
and (b) the principal can implement e satisfying (5.3) for each agent with lower costs under side contracting on efforts than under no side contracting.

The first assertion is immediately obtained from (5.2). The intuition is that unequal risk allocation between two outputs for an agent is canceled out by the unequal risk allocation for the other agent. Thus, their coordinated effort choice is always based on equal risk allocation between two outputs in total. The proof of the second assertion is similar to that of Theorem 3 , and so is omitted.

Although here the agents are homogeneous and no multiple equilibrium problem exists, the principal cannot implement all the symmetric effort pairs when agents side contract on efforts. Condition (5.3) is similar to (4.2), implying that the agents allocate their efforts efficiently between two tasks. The theorem implies that if the principal wants each of them to do so, that she prefers the agents to coordinate their effort choice. However, the second-best effort pair is not necessarily efficient in this sense even in the symmetric situation, unless there are some exogenous reasons in favor of "egalitarianism." To see this, note that by (5.1), condition (5.3) holds if and only if $v_{L H}^{1}=v_{H L}^{1}$ : When the principal wishes for efficient allocation of efforts, she must also allocate risk imposed on each agent equally between the outputs from two tasks. This is achieved by nonpersonalized reward when one output is high and the other is low, regardless of which output is high and which is low. In other words, the principal pays each agent contingent only on the aggregate output: the scheme is completely team-based (at least in this two-outcome case).

The second-best symmetric effort satisfies (5.3) in the following simple specification of the model: Suppose that $p(a, b)=p(a+b)$ and $G(a, b)=g(a)+h(b)$ with $g$ and $h$ strictly convex and $g^{\prime}(0)=h^{\prime}(0)=0$. Itoh (1991a) shows that under such a specification, the second-best efforts have positive helping effort as well as positive own effort. Given the total amount of effort $a+b, a$ and $b$ are then determined by $g^{\prime}(a)=h^{\prime}(b)$ : If $g^{\prime}(a)>h^{\prime}(b)\left(g^{\prime}(a)<h^{\prime}(b)\right)$, the principal could reduce the implementation costs by decreasing $a(b)$ and increasing $b(a)$ while keeping $a+b$ fixed. Thus, effort coordination is preferred by the principal in this specific case. $^{18}$

Another simple case in which the principal prefers effort coordination to no coalition is

18 Further analysis of this case is found in Itoh (1990). 
the "pure allocation" model: $p(a, b)=p(a+b)$ and $G(a, b)=G(a+b)$. Then (5.3) holds for any symmetric effort pair. This is the case analyzed by Ramakrishnan and Thakor (1990). They focus on the case of pure allocation, while they extend their analysis to the case in which two outputs are correlated with each other. ${ }^{19}$

\section{Effort Coordination and Relative Performance Evaluation}

The argument in the preceding two sections can be extended to more general cases in which both correlation in noise terms and any form of production externalities exist. What has been shown there is that the principal prefers effort coordination to no coalition when the optimal compensation for homogeneous agents is perfectly correlated with each other in the absence of coalition, that is, they are paid equally in each outcome. Let me call such a scheme egalitarian. When coalition is not taken into account, egalitarian schemes are generally not optimal even in symmetric situations. However, if the principal can encourage coordination of efforts among agents under egalitarian schemes, it may outperform the second-best schemes with no coalition. Thus, the principal has stronger incentives to adopt egalitarian, teambased incentive schemes for homogeneous agents than models without the possibility of side contracting on efforts predict.

Egalitarian schemes are never optimal in the absence of coalition when no production externality exists and there exists systematic risk so that relative performance evaluation is optimal, that is, each agent is paid higher the lower the output of the other agent is: compensation is negatively correlated. In an extreme case where rank-order tournament schemes are adopted, encouraging effort coordination hurts the principal: If an optimal coalition-free schedule for an effort pair is a rank-order tournament, the principal cannot reduce the risk imposed on each agent without altering their incentives to select the same efforts. Coalition under tournaments only leads homogeneous agents to choose the least costly efforts. The negative effect of effort coordination seems to persist when the correlation between the error terms is sufficiently high, if not perfect. Holmstrom and Milgrom (1990) and Ramakrishnan and Thakor (1990) recently show in their specific models that there exists a cut-off value for measures of the degree of correlation between the error terms (e.g., correlation coefficient)

19 Their analysis is also different from my analysis in that they assume effort sharing is infeasible $(b=0)$ in the absence of coalition (or, in their context, in the case of no merger). 
such that effort coordination is preferred to no coalition if and only if the degree of correlation is lower than that threshold level. While my model is too general to obtain such a clear result, the same basic logic appears to hold.

Thus, the analyses in this paper suggest that encouraging coordination in effort choice is better the less important systematic risks are relative to production externalities because relative performance evaluation encourage negative externalities like "sabotage" (Lazear, 1989), or the less costly it is to avoid rank-order tournaments. For example, some "prizes" are indivisible or limited in numbers so that competitive schemes are unavoidable (e.g., promotions to higher-ranked job titles). Then coalition should be discouraged.

\section{Non-Existence of Coalition-Proof Revelation Mechanisms}

The analyses in the foregoing sections compare the case of effort coordination by agents through side contracts with the benchmark case of no coalition, in which the principal attains the standard second-best solution via appropriate incentive contracts. As I discussed in Introduction, I therefore exclude the possibility that the principal designs a revelation mechanism to induce the agents to report their efforts to her, because of the incompleteness in contracts.

In this section, I show that under the full-side-contract assumption, the principal would have no incentive to design such a revelation mechanism, if possible, and hence would leave the coordination of efforts to the agents who monitor each other's efforts and attain coordination. ${ }^{20}$ The logic behind this result is quite simple: under any revelation mechanism that improves the principal's welfare, the agents would find an effort pair they both prefer, and collude to choose that pair and appropriate messages to the principal.

I extend the general model presented in Section 2 to include communication stages. Let $M_{n}$ be the set of a sequence of messages sent to the principal by agent $n$ and $m_{n}$ be its generic element. Each $m_{n}$ consists of two kinds of messages and is denoted as $m_{n}=\left(m_{n}^{O}, m_{n}^{N}\right)$ where $m_{n}^{O}$ is a sequence of messages observable to the other agent, and $m_{n}^{N}$ is a sequence of messages unobservable to the other agent (observable only to agent $n$ and the principal). Communication stages are summarized by reporting strategies of the agents. Let $s_{1}: M_{2} \times E \rightarrow M_{1}$ be the

20 If the agents can monitor each other's efforts and do not side contract, there exists a revelation mechanism that can implement the first-best solution as a unique sequential equilibrium (Ma, 1988). Of course, such a mechanism requires that the principal be able to contract on efforts. 
reporting strategy of agent 1 , which determines his messages dependent on the messages sent by agent 2 and the efforts chosen by the agents: $E$ is the set of feasible effort pairs. Of course, $s_{1}$ depends only on the part of agent 2 's messages that are observable to agent 1 . The reporting strategy of agent $2 s_{2}: M_{1} \times E \rightarrow M_{2}$ is similarly defined.

Example. Consider Ma (1988)'s mechanism which attains the first-best solution when the efforts are mutually observable between agents, given that no side contract is possible. There, after both agents selecting efforts and observing them, agent 1 reports an effort pair to the principal. After observing that effort, agent 2 can "agree" or "challenge," and in the latter case, reports a different effort pair. The report of agent 2 is also observable to agent 1 . In the notation here, this mechanism is described as follows:

$$
\begin{aligned}
& m_{1}=s_{1}\left(e_{1}, e_{2}\right) \in E \\
& m_{2}=s_{2}\left(m_{1}, e_{1}, e_{2}\right) \in\{\text { agree, challenge }\} \times E .
\end{aligned}
$$

The payoff to agent $n$ is determined by not only outcomes but also messages he has sent to the principal, and the part of messages of the other agent that are observable to agent $n$. Let $v_{i j}^{1}\left(m_{1}, m_{2}^{O}\right)$ and $v_{i j}^{2}\left(m_{2}, m_{1}^{O}\right)$ be the payoffs to agents 1 and 2 , respectively, when $\left(m_{1}, m_{2}\right)$ has been reported to the principal, and the true outcomes are $(i, j) \in \Omega_{1} \times \Omega_{2}$.

Fix an effort pair $\left(e_{1}, e_{2}\right)$. The principal designs a mechanism so as to implement this effort pair with least costs. I do not need to specify exactly how each mechanism implements the efforts. Suppose that there exists a mechanism which can implement $\left(e_{1}, e_{2}\right)$. Let $\left(\bar{m}_{1}, \bar{m}_{2}\right)$ be the messages actually sent under that mechanism. For my purpose it is then sufficient to note that because of the full-side-contract assumption, the mechanism should be coalitionproof: Under the mechanism, the agents cannot find a pair of efforts $\left(\hat{e}_{1}, \hat{e}_{2}\right)$ and a pair of messages observable between them, $\left(\hat{m}_{1}^{O}, \hat{m}_{2}^{O}\right)$, such that they Pareto dominate $\left(e_{1}, e_{2}\right)$ and $\left(\bar{m}_{1}^{O}, \bar{m}_{2}^{O}\right)$. Then the following result holds.

THEOREM 7. Suppose that transferable utility exists. Then there does not exist a coalitionproof mechanism which implements a given effort pair with lower costs than the optimal contracts for effort coordination case can do without revelation of the agents' efforts to the principal.

Proof: Suppose that such a mechanism exists. Using the notations above, let $\left(\bar{v}_{i j}^{n}\right)$ be the compensation scheme actually rewarded to agent $n$ in the mechanism: For example, $\bar{v}_{i j}^{1}=$ 
$v_{i j}^{1}\left(\bar{m}_{1}, \bar{m}_{2}^{O}\right)$. Since by assumption $\left(\bar{v}^{1}, \bar{v}^{2}\right)$ are less costly to the principal than the optimal contracts solving (EC), the former schemes should not be feasible under problem (EC). Noting that transferable utility exists and that the mechanism must be coalition-proof, it implies that (TCIC 2) must be violated: there must exist an effort pair $\left(\bar{e}_{1}, \bar{e}_{2}\right)$, different from $\left(e_{1}, e_{2}\right)$, such that

$$
\begin{aligned}
& \sum_{i} \sum_{j} P_{i j}\left(\bar{e}_{1}, \bar{e}_{2}\right)\left(\bar{v}_{i j}^{1}+\bar{v}_{i j}^{2}\right)-G_{1}\left(\bar{e}_{1}\right)-G_{2}\left(\bar{e}_{2}\right) \\
& >\sum_{i} \sum_{j} P_{i j}\left(e_{1}, e_{2}\right)\left(\bar{v}_{i j}^{1}+\bar{v}_{i j}^{2}\right)-G_{1}\left(e_{1}\right)-G_{2}\left(e_{2}\right) .
\end{aligned}
$$

However, the agents are then better off by agreeing to choose $\left(\bar{e}_{1}, \bar{e}_{2}\right)$ and send messages $\left(\bar{m}_{1}^{O}, \bar{m}_{2}^{O}\right)$ under the mechanism, which contradicts the coalition-proofness of the mechanism.

Q.E.D.

The theorem shows obviously that when agents side contract on efforts, coalition-proof mechanisms add nothing more to the principal than she can attain without knowing their private information. ${ }^{21}$ One can therefore interpret the incentive system considered in this paper as a sort of delegation mechanism: the principal delegates arrangement of cooperation to the agents who coordinate their actions via mutual monitoring and side contracting. Such delegation benefits the principal under the conditions shown in the paper.

\section{Concluding Remarks}

The main conclusion of this paper is that the principal sometimes prefers her agents to behave as a group than to behave independently (or competitively). Under the assumption that the agents freely side contract on what they can commonly observe, coalitional behavior is of value to the principal only if the agents share some private information. If the agents can monitor each other's actions perfectly, the principal can delegate coordination of actions to the agents, and such a delegation is likely to be beneficial under (a) individualistic production without substantial systematic risk; (b) team production with sufficiently homogeneous agents; (c) workplace with a lot of interaction among homogeneous agents (who perform multiple tasks) and with pressure to egalitarianism.

21 The result depends on the existence of transferable utility. If transferable utility did not exist, revelation mechanisms could be of value to the principal because she could improve payoff allocation between the agents by centralizing their private information. 
The full-side-contract assumption is very important for these results. ${ }^{22}$ Although I take the coalitional behavior as an assumption throughout the paper, the future research should treat it as endogenous, stemming from organizational design, and ask when side contracting behavior arises. To induce coalitional behavior, the principal should enable the agents to enforce their side contracts easily. Here I discuss three types of enforcement mechanisms.

First mechanism is reputation. Economists' explanation of cooperation by self-interested agents involves repetition of a one-shot decision making situation. Loosely speaking, the literature on repeated games shows that cooperation can be attained as a perfect Nash equilibrium of the repeated game if the one-shot game is repeated sufficiently many times, the players can observe each other's actions perfectly after each one-shot game, and they discount their future payoffs sufficiently small. See, for example, Fudenberg and Maskin (1986).

Of course, under long-term relationships, the principal has an incentive to design longterm contracts based on repeated observations of agents' outputs for the purpose of risk spread over time. Thus, one might doubt the validity of the static representation of the model in the paper, provided that long-term relationships are necessary for enforcement of side contracts. However, this argument merely strengthens our result that coalitional behavior is beneficial to the principal: the principal is better off by encouraging coalition via long-term relationships by and spreading risk over time than by keeping relationships short. What has been shown is that even without the possibility of risk spread over time, long-term relationships could be advantageous to the principal because they make enforcement of beneficial coalition among agents easier.

Second mechanism is related to the first one. Suppose that the relationship between the principal and the agents is one shot while the agents have other opportunities to transact with each other (or maybe with other common principals). One example is "social relation" among agents. They may spend resources to reduce their disutility of work, for example, by showing respects, cheering up each other, listening to others' complaints, and so on. If the agents interact with each other in other occasions, their cooperation could be induced. ${ }^{23}$

22 The benefit of "cooperation" among agents can be explained without this assumption, however. When there are production externalities, observation of mutual help does not imply that agents are behaving as a group, because with appropriate pay schemes, they could help each other for their own interests. And the principal sometimes prefers such cooperation to competition among them (Itoh, 1990, 1991a).

23 Casual observation indicates that in Japanese firms work groups are the primary func- 
For example, see Hirshleifer and Rasmusen (1989) and Okuno (1984) for ostracism enforcing cooperation.

The last mechanism is associated with laboratory experiments on human cooperation. The literature identifies other factors to derive cooperation. (See Dawes and Thaler (1988) for a survey and references.) It is typical that cooperation can be observed even in one-shot experiments. And some experiments find that cooperation rates are significantly higher when discussion is allowed before the decision than not, and given discussion, when each subject is told that his/her cooperation improves the welfare of the other members in the team to which he/she belongs, rather than those in the other team (Ordell et al., 1988). This latter condition is called "group identity" by the authors. Frank (1988) attributes such results to the importance of emotions. He writes:

To cheat a stranger and to cheat someone you have met personally amount to precisely the same thing in rational terms. Yet, in emotional terms, they are clearly very different. Face-to-face discussion, even if not directly relevant to the game itself, transforms the other players from mere strangers into real people. Discussion about what is the "right" thing to do in prisoner's dilemmas further arouses the relevant emotions. And still higher levels of emotional involvement are evoked by explicit promises to cooperate. (Frank, 1988, pp. 224-225.)

He then goes on to argue that it is important for the firm to design a working environment that encourages the emotions supporting cooperation in order to increase propensity to cooperate.

This paper has focused on coalition among agents which benefits principals. Of course, coalition has costs as well. Tirole (1986) fully discusses detrimental coalition (manipulation of information) based on his analysis of vertical relationships of a principal, a supervisor, and an agent. The analyses in Sections 4 and 5 point out another source of the costs: the loss of control over the agents' effort allocation. Since encouraging cooperation tends to encourage collusion as well, the net benefits from coalitional behavior may be smaller than we expect

tional units rather than individual jobs (Aoki, 1988; Kagono et al., 1985; Lincoln and McBride, 1987). Enforcement of coalitional behavior seems easier there than in Western firms partly because of longer tenure of Japanese employees. It is also interesting to find that there are far more opportunities for interpersonal contacts in Japanese firms than in Western counterparts, such as no personal office, teamwork, food/housing/medical facilities, or vacation tours for employees. 
from the results of the paper. We will need to analyze the tradeoff between costs and benefits of coalitional behavior more explicitly.

We should also look for how to avoid detrimental coalition while encourage beneficial coalition, if any. One possible way is to reward agents more by promotion than by monetary pay. Promotion to more visible tasks and evaluation of supervisors based on their subordinates' future performance could alleviate their incentives to misrepresent information via collusion, without losing benefits from cooperation among agents. Another possibility is the use of job rotations both within and across work groups. Regular job rotations within a group facilitate mutual monitoring and sanctioning among workers in the group and thereby effort coordination (without increasing the danger of detrimental coalition). On the other hand, job rotations across groups, factories, or divisions typically accompany changes of bosses, which practice keeps vertical relationships short and hence restricts side transfers. Of course, the latter type of job rotations will also make the relationship among workers short, while the former type will complement this shortcoming. ${ }^{24}$

24 See Itoh (1991b) for applications of these ideas to Japanese human resource management. 


\section{References}

AokI, M. (1988): Information, Incentives, and Bargaining in the Japanese Economy. Cambridge: Cambridge University Press.

Baiman, S. And J. S. Demski (1980): "Economically Optimal Performance Evaluation and Control Systems," Journal of Accounting Research, vol. 18, pp. 184-220.

BARON, J. N. (1988): "The Employment Relation as a Social Relation," Journal of the Japanese and International Economies, vol. 2, pp. 492-525.

Dawes, R. M. And R. H. Thaler (1988): "Anomalies: Cooperation," Journal of Economic Perspectives, vol. 2, pp. 187-197.

DE Groote, X. (1988): The Strategic Choice of Production Processes. Ph.D. Thesis, Graduate School of Business, Stanford University.

Demski, J. S. And D. Sappington (1984): "Optimal Incentive Contracts with Multiple Agents," Journal of Economic Theory, vol. 33, pp. 152-171.

Drago, R. And G. K. Turnbull (1988): "Individual versus Group Piece Rates under Team Technologies," Journal of the Japanese and International Economies, vol. 2, pp. 1-10.

Fran K, R. H. (1988): Passions within Reason: The Strategic Role of the Emotions. New York: W.W.Norton.

Fudenberg, D. and E. Maskin (1986): "The Folk Theorem in Repeated Games with Discounting or with Incomplete Information," Econometrica, vol. 54, pp. 533-554.

Granovetter, M. (1985):"Economic Action and Social Structure: The Problem of Embeddedness," American Journal of Sociology, vol. 91, pp. 481-510.

Green, J. R. And N. L. Stokey (1983): "A Comparison of Tournaments and Contracts," Journal of Political Economy, vol. 91, pp. 349-364.

Grossman, S. J. and O. D. Hart (1983): "An Analysis of the Principal-Agent Problem," Econometrica, vol. 51, pp. 7-45.

(1986): "The Costs and Benefits of Ownership: A Theory of Vertical and Lateral Integration," Journal of Political Economy, vol. 94, pp. 691-719.

Hirshleifer, D. and E. Rasmusen (1989): "Cooperation in a Repeated Prisoners' Dilemma with Ostracism," Journal of Economic Behavior and Organization, vol. 12, pp. 87-106.

Holmström, B. (1982): "Moral Hazard in Teams," Bell Journal of Economics, vol. 13, pp. 324-340.

Holmstrom, B. And P. Milgrom (1987): "Aggregation and Linearity in the Provision of Intertemporal Incentives," Econometrica, vol. 55, pp. 303-328.

(1990): "Regulating Trade among Agents," mimeo. Yale University.

Iтон, H. (1988): Essays on Internal Organization of the Firm. Ph.D. thesis, Graduate School of Business, Stanford University, March. 
(1990): "Cooperation in Hierarchical Organizations: An Incentive Perspective,"

metrica (1991a): "Incentives to Help in Multi-Agent Situations," forthcoming in Econometrica. Theory," mimeo.

Kagono, T., I. Nonaka, K. Sakakibara and A. Okumura (1985): Strategic vs. Evolutionary Management: A U.S.-Japan Comparison of Strategy and Organization. Amsterdam: North-Holland.

LAFFont, J.-J. (1990): "Analysis of Hidden Gaming in a Three-Level Hierarchy," Journal of Law, Economics, and Organization, vol. 6, pp. 301-324.

Lazear, E. P. (1989): "Pay Equality and Industrial Politics," Journal of Political Economy, vol. 97, pp. 561-580.

Lazear, E. P. And S. Rosen (1981): "Rank-Order Tournaments as Optimal Labor Contracts," Journal of Political Economy, vol. 89, pp. 841-864.

Levine, D. I. And L. D. Tyson (1990): "Participation, Productivity, and the Firm's Environment," in A. S. Blinder (ed.), Paying for Productivity: A Look at the Evidence. Washington, D.C.: The Brookings Institution, pp. 183-237.

LinColn, J. R. And K. MCBRide (1987): "Japanese Industrial Organization in Comparative Perspective," Annual Review of Sociology, vol. 13, pp. 289-312.

MA, C. (1988): "Unique Implementation of Incentive Contracts with Many Agents," Review of Economic Studies, vol. 55, pp. 555-571.

Ma, C., J. Moore and S. Turnbull (1989): "Stopping Agents from Cheating," Journal of Economic Theory, vol. 46, pp. 355-372.

Macho-Stadler, I. And J. D. Pérez-Castrillo (1990): "Moral Hazard with Several Agents: the Gains from Cooperation," mimeo.

MarschaK, J. And R. Radner (1972): Economic Theory of Teams. New Haven: Yale University Press.

Mookherjee, D. (1984): "Optimal Incentive Schemes with Many Agents," Review of Economic Studies, vol. 51, pp. 433-446.

Mookherjee, D. and S. Reichelstein (1988): "Implementation via Augmented Revelation Mechanisms," Review of Economic Studies, vol. 57, pp. 453-475.

Nalbantian, H. R. (1988): "Incentive Compensation in Perspective," in H. R. Nalbantian (ed.), Incentives, Cooperation, and Risk Sharing. Savage: Rowman and Littlefield, pp. 3-43.

Nalebuff, B. J. And J. E. Stiglitz (1983): "Prizes and Incentives: Toward a General Theory of Compensation and Competition," Bell Journal of Economics, vol. 14, pp. 21-43.

OKuno, M. (1984): "Corporate Loyalty and Bonus Payments: An Analysis of Work Incentives in Japan," in M. Aoki (ed.), The Economic Analysis of the Japanese Firm. Amsterdam: North-Holland. 
Orbell, J. M., A. J. C. van de Kragt, and R. M. Dawes (1988): "Explaining DiscussionInduced Cooperation," Journal of Personality and Social Psychology, vol. 54, pp. 811-819.

Perrow, C. (1986): Complex Organizations: A Critical Essay (3rd ed.). New York: Random House.

RAdner, R. (1962): "Team Decision Problems," Annals of Mathematical Statistics, vol. 33, pp. 857-881.

Ramakrishnan, R. T. S. And A. V. Thakor (1990): "Cooperation versus Competition in Agency," mimeo. School of Business, Indiana University, August.

Rogerson, W. P. (1985): "The First-Order Approach to Principal-Agent Problems," Econometrica, vol. 53, pp. 1357-1367.

Tirole, J. (1986): "Hierarchies and Bureaucracies: On the Role of Collusion in Organizations," Journal of Law, Economics, and Organization, vol. 2, pp. 181-214.

- (1988): "The Multicontract Organization," Canadian Journal of Economics, vol. 21, pp. 459-466.

VARIAN, H. R. (1989): "Monitoring Agents with Other Agents," CREST Working Paper, University of Michigan.

Williamson, O. E. (1985): The Economic Institutions of Capitalism: Firms, Markets, Relational Contracting. New York: The Free Press. 


\section{Appendix}

\section{Proof of Theorem 3.}

Suppose that $\left(v_{i}\right)$ is the optimal coalition-free scheme for a given effort pair $(e, e)$. Define the new scheme $\left(\hat{v}_{i}\right)$ by

$$
\hat{v}_{i}=\frac{1}{2} v_{i}+\frac{1}{2} H
$$

for each $i$, where $H=\bar{U}+G(e)$. The new schedule clearly satisfies (PC).

To show that (CIC 2) holds under the new schemes, I first show that $(e, e)$ maximizes the sum of the agents' expected utilities under the new scheme, which is equal to

$$
p\left(e_{1}, e_{2}\right) v_{H}+\left(1-p\left(e_{1}, e_{2}\right)\right) v_{L}-G\left(e_{1}\right)-G\left(e_{2}\right)+H \text {. }
$$

To see this, note that $(e, e)$ is a person-by-person maximizing effort pair of (A2). And the convexity of $p(\cdot)$ implies that (A2) is convex in $\left(e_{1}, e_{2}\right)$. This is then sufficient for $(e, e)$ to be a global maximizer of (A1). (See Marschak and Radner (1972), Theorem 5.1.) Then as in the proof of Theorem 2, (CIC 2) is in fact satisfied by setting $\hat{U}^{2}$ equal to the agent 2's expected utility. Because the expected utility of agent 1 is also equal to $\hat{U}^{2}$, the new scheme satisfies (CIC 1) with $\lambda=1$.

To see (CIC 3 ) hold, let $\left(e^{N}, e^{N}\right)$ be a Nash equilibrium selected by the agents when they do not reach agreement. Then since $(e, e)$ maximizes the sum of the agents' expected utilities $(\mathrm{A} 2), p(e, e) v_{H}+(1-p(e, e)) v_{L}-2 G(e) \geq p\left(e^{N}, e^{N}\right) v_{H}+\left(1-p\left(e^{N}, e^{N}\right)\right) v_{L}-2 G\left(e^{N}\right)$ holds. This leads to

$$
\begin{aligned}
p(e, e) \hat{v}_{H}+(1-p(e, e)) \hat{v}_{L}-G(e) & =\frac{1}{2}\left(p(e, e) v_{H}+(1-p(e, e)) v_{L}-2 G(e)\right)+\frac{1}{2} H \\
& \geq \frac{1}{2}\left(p\left(e^{N}, e^{N}\right) v_{H}+\left(1-p\left(e^{N}, e^{N}\right)\right) v_{L}-2 G\left(e^{N}\right)\right)+\frac{1}{2} H \\
& =\frac{1}{2}\left(p\left(e^{N}, e^{N}\right) v_{H}+\left(1-p\left(e^{N}, e^{N}\right)\right) v_{L}\right)-G\left(e^{N}\right)+\frac{1}{2} H
\end{aligned}
$$

Thus, each agent's expected utility under $(e, e)$ is at least as large as that under $\left(e^{N}, e^{N}\right)$.

The principal's expected payments are smaller under $\left(\hat{v}_{i}\right)$ than under $\left(v_{i}\right)$ by Jensen's inequality and the fact that $\left(v_{i}\right)$ satisfies $(\mathrm{PC})$. Thus, the principal is better off under the new scheme.

Finally, by the same argument as in the proof of Theorem 2, the agents, once they accept the initial contract, follow the instruction of the principal concerning their coordinated efforts. 


\section{Proof of Theorem 4}

Let $\left(v_{L}, v_{H}\right)$ be the optimal coalition-free schemes implementing $(e, e)$. Since $e$ is not least costly, $v_{H}>v_{L}$ holds. It is sufficient to show that the schemes defined by (A1) satisfy constraints (CIC 2). And to show this, it is sufficient to show that $(e, e)$ maximizes the sum of the agents' expected utilities given in (A2). Let $\left(e_{1}^{\prime}, e_{2}^{\prime}\right)$ maximize (A2) and suppose that $(e, e)$ does not. Then,

$$
p\left(e_{1}^{\prime}, e_{2}^{\prime}\right)\left(v_{H}-v_{L}\right)-G\left(e_{1}^{\prime}\right)-G\left(e_{2}^{\prime}\right)>p(e, e)\left(v_{H}-v_{L}\right)-2 G(e) .
$$

Since $(e, e)$ is a dominant Nash equilibrium under the original schemes, we have

$$
p\left(e_{1}^{\prime}, e_{2}^{\prime}\right)\left(v_{H}-v_{L}\right)-G\left(e_{n}^{\prime}\right) \leq p(e, e)\left(v_{H}-v_{L}\right)-G(e)
$$

for $n=1,2$. These two inequalities yield $G\left(e_{n}^{\prime}\right)<G(e)$, and hence $e_{n}^{\prime}<e$ for each $n$. Then

$$
\begin{aligned}
& {\left[p(e, e)\left(v_{H}-v_{L}\right)-2 G(e)\right]-\left[p\left(e_{1}^{\prime}, e_{2}^{\prime}\right)\left(v_{H}-v_{L}\right)-G\left(e_{1}^{\prime}\right)-G\left(e_{2}^{\prime}\right)\right]} \\
& \quad=\left(p(e, e)-p\left(e, e_{2}^{\prime}\right)\right)\left(v_{H}-v_{L}\right)+\left(p\left(e, e_{2}^{\prime}\right)-p\left(e_{1}^{\prime}, e_{2}^{\prime}\right)\right)\left(v_{H}-v_{L}\right)-\delta G_{1}-\delta G_{2} \\
& \quad \geq\left(p(e, e)-p\left(e, e_{2}^{\prime}\right)\right)\left(v_{H}-v_{L}\right)+\left(p(e, e)-p\left(e_{1}^{\prime}, e\right)\right)\left(v_{H}-v_{L}\right)-\delta G_{1}-\delta G_{2} \\
& \quad \geq \delta G_{2}+\delta G_{1}-\delta G_{1}-\delta G_{2}=0
\end{aligned}
$$

where $\delta G_{n}=G(e)-G\left(e_{n}^{\prime}\right)$. The first inequality follows from (4.1) and the second inequality holds because $(e, e)$ is a Nash equilibrium. This contradicts (A3). Thus, $(e, e)$ maximizes the sum of the agents' expected utilities under the new schemes defined by (4.1), which implies that (CIC 2) is satisfied. 